Quebec Cooperative Study

of Friedreich's Ataxia

\title{
Hypertrophic Cardiomyopathy in Friedreich's Ataxia: Symmetric or Asymmetric?
}

\author{
A. Pasternac, R. Król, R. PetitClerc. C. harvey, E. ANDERmanN and A. Barbeau
}

SUMMARY: We evaluated 15 patients with Friedreich's ataxia ( $F A)$ to define the incidence of miocardial involvement and the lipe of cardiomyopaty observed.

Ail parients with FA had either ECG, vectocardiographic or echocardiographic abnormalities, suggesting some degree of miocardial involvement. In contrast to reports indicating that aslmmetric septal hipertrophy $(A S H)$, often obstructive, is associated with FA, symmetric, concentric hypertrophic cardiomyopathy (SCH) was the predominant abnormality (sixty'-seven percent of patients). Echocardiograms should be performed periodicall! in all $F A$ parients since this technique allow's the detection of cardiac hypertrophy.

RESUMÉ: Nous avons étudie 15 patients porteurs d'Alaxie de Friedreich ( $A F$ ) pour définir l'incidence d'atteinte myocardique et le type de cardiomyopathie observée dans celte condition.

Tous les patients atteints de AF avaient des anomalies soit de I'ECG, du vectocardiogramme ou de l'échocardiogramme suggérant un cerlain degré d'atteinte myocardique. A la différence des rapports de la littérature, qui indiquent qu'une hypertrophie septable asymétrique ( $A S H)$, souvent obstructive, est associee da $A F$, nous avons observé quiune cardiomyopathie hypertrophique concentrique était l'anomalie habituelle (soixante-sept pourcent des patients). Des échocardiogrammes périodiques devraient être pratiqués chez tous les patients porteurs de A $F$ de façon à détecter cette cardiomyopathie hypertrophique.

From the Montreal Heart Institute, the University of Montreal and the Department of Neurogenetics, the Montreal Neurological Hospita! and Institute. McGill University, Montreal, Quebec, Canada.

Reprint requests for the complete supplement on Friedreich's ataxia (Phase III) to: Dr. André Barbeau. Clinical Research Institute of Montreal, 110 Pine Avenue West, Montreal, Quebec, Canada H2W 1R7.
The incidence of cardiac manifestations in Friedreich's ataxia varies widely from one series to another, in part because different criteria have been used by various investigators (Hewer, 1969; Thoren, 1964; Côté et al, 1976). Nearly $40 \%$ of the patients present with cardiac symptoms, but the incidence of electrocardiographic and echocardiographic abnormalities is notably higher (Côté et al, 1976).

In the last few years, the occurrence of asymmetric septal hypertrophy (ASH), often of the obstructive type, has frequently been reported in patients with Friedreich's ataxia (Smith et al, 1977; Pernot, 1979), to the extent that some authors have proposed that ASH is the usual type of cardiomyopathy encountered in FA (Smith et al, 1977; Gach et al, 1971; Ruschhaupt et al, 1973). However, this is based on isolated case-reports and small series of patients.

Since $50 \%$ of FA patients die from cardiac causes (Boyer et al, 1962), early detection and management of heart disease may improve their prognosis and quality of life. This is all the more relevant now that pharmacologic treatment by calcium-antagonists may alter the course of the hypertrophic cardiomyopathy (Rosing et al, 1979a; 1979b; Troesh et al, 1979).

The purpose of this study was therefore two fold:

1. To assess the frequency of the myocardial involvement in Friedreich's ataxia;

2. To determine whether there is a specific type of cardiomyopathy in patients with Friedreich's ataxia.

\section{METHODS}

The study comprised 15 randomly selected patients with clinically typical Friedreich's ataxia previously diag- nosed during phase I of the Quebec Collaborative Study. There were 10 males and 5 females with a mean age of 27.6 years (range 13-45). All had complete clinical examination, 12-lead electrocardiogram, a vectorcardiogram and M-mode and bi-dimensional echocardiogram. All examinations were performed and interpreted by independent observers. The vectorcardiogram (Hewlett-Packard 1520-A) was recorded using Frank lead system and photographs of the frontal, horizontal and left sagittal planes were taken on Polaroid film and analyzed according to accepted norms for all age groups (Kisslo et al, 1976).

M-mode and bi-dimensional echocardiograms were obtained with Picker Echoview $80 \mathrm{C}$ coupled with a Honeywell 1856 strip chart recorder. All patients were examined in the $30^{\circ}$ left lateral position. For the M-mode study, we used a $2.25 \mathrm{MHz}$ transducer and for the cross-sectional study, we used a $60^{\circ}$ angle mechanical transducer. Images were recorded and stored on videotape for subsequent analysis.

Left ventricular minor axis dimension was measured between the endocardial surface of the posterior wall and the interventricular septum. The left ventricular end-diastolic dimension (LVIDd) was measured at the level of the chordae tendinae at the peak of the $R$ wave of a simultaneously recorded ECG. The left ventricular end-systolic dimension (LVIDs) was taken as the smallest distance between the endocardial surfaces during systole. End-diastolic septal and left ventricular posterior wall thickness (ST and PWT) were measured from the endocardial to epicardial surfaces at the peak of the $R$ wave of the ECG. Right septal wall echoes were demarcated by proper damping. Fractional shortening 
of the minor axis (\% sh) was calculated as: $\%$ sh $=($ LVIDd - LVIDs $) /$ LVIDd.

\section{RESULTS}

The clinical, electrocardiographic and echocardiographic data of all patients are shown in tables 1 and 2 .

\section{Clinical results}

Cardiac symptoms were present in 9 patients $(60 \%)$; these included palpitations, exertional dyspnea, and non characteristic chest pain. In patients with neurologic disability and chest deformities, shortness of breath and chest discomfort may not reflect cardiac involvement. One patient ( $\#$ 8) had signs of slight congestive heart failure on physical examination. One patient was in atrial fibrillation ( $\# 8)$.

\section{Electrocardiographic data}

All patients had an abnormal electrocardiogram and vectorcardiogram. On ECG, the most frequent abnormalities were negative $T$ waves and ST depression in inferolateral leads. Two patients (\#2,\#6) had right ventricular hypertrophy (RVH) on ECG and VCG. In patient 5, RVH was suggested by the ECG but not confirmed on VCG. In all remaining patients, there were no differences between ECG and VCG findings, so that only ECG results are indicated in table 1.

One patient ( $\# 2$ ) had biventricular hypertrophy and one (\#3) had left ventricular hypertrophy (LVH) on ECG and VCG.

\section{Echocardiographic data}

Two patients ( $\# 2, \# 6$ ) had a systolic ejection murmur along the left sternal border. Both had symmetric left ventricular hypertrophy on the echocardiogram and one ( $\# 2$ ) had a systolic anterior motion of the anterior mitral leaflet (SAM) and hypertrophied papillary muscles.

In total, II patients $(73 \%)$ had echocardiographic abnormalities: ten had symmetric LVH, defined as ST and PWT > $13 \mathrm{~mm}$; one patient ( $\#$ 8) had a paradoxical septal motion and a lack of thickening of the septum and of the left ventricular posterior wall in systole, indicating a diffuse cardiomyopathic process. In all patients, the ST/ PWT ratio was approximately 1.0. In addition. one patient (\#6) with symmetric LVH also had a holosystolic mitral valve prolapse.

\section{DISCUSSION}

The incidence of reported cardiac involvement in Friedreich's ataxia varies from $30 \%$ to $80 \%$. The major pathological features are muscle fiber hypertrophy, diffuse myocardial fibrosis, ventricular hypertrophy, and varying degrees of narrowing of middle and small size coronary arteries (Hewer, 1969). In our series, all patients demonstrated some kind of myocardial involvement, because of electrocardiographic and echocardiographic abnormalities, often in the

TABLE 1

Clinical Data

\begin{tabular}{|c|c|c|c|c|c|c|}
\hline$\#$ & $\mathbf{P t}$ & Age & Sex & Symptoms & Auscultation & ECG \\
\hline 1 & G.L. & 13 & $\mathbf{F}$ & effort dyspnea & 1/6 systolic, apical murmur & WPW A \\
\hline 2 & B.L. & 17 & M & $\begin{array}{l}\text { effort dyspnea, palpitations } \\
\text { atypical angina }\end{array}$ & 3/6 S. ejection murmur & LVH, RVH neg. \\
\hline 3 & G.S. & 17 & M & palpitation, atypical angina & S 4 & LVH, neg. T lat. \\
\hline 4 & G. M. & 17 & M & $\begin{array}{l}\text { effort dyspnea, atypical } \\
\text { angina }\end{array}$ & normal & $\mathrm{RBB}$ \\
\hline 5 & J.P. & 21 & M & palpitation & systolic click & Left ant. hemiblock \\
\hline 6 & M.R. & 28 & $\mathbf{M}$ & palpitation, atypical angina & $2 / 6 \mathrm{~S}$. ejection murmur & $\begin{array}{l}\text { RVH, sinus tachy. } \\
\text { neg. } T \text { inf. }\end{array}$ \\
\hline 7 & C.G. & 29 & $\mathrm{~F}$ & effort dyspnea & $\mathrm{S} 3, \mathrm{~S} 4$ & neg. $T$ inf-lat. \\
\hline 8 & L.M. & 31 & M & $\begin{array}{l}\text { palpitation, effort dyspnea, } \\
\text { atypical angina }\end{array}$ & normal & $\begin{array}{l}\text { atr. fibr. VPC'S, } \\
\text { neg. T lat. }\end{array}$ \\
\hline 9 & H.P. & 32 & $\mathbf{F}$ & $\begin{array}{l}\text { effort dyspnea, atypical } \\
\text { angina }\end{array}$ & normal & neg. $T$ inf-lat. \\
\hline 10 & M.O. & 21 & $\mathbf{M}$ & none & normal & neg. $T$ inf-lat. \\
\hline 11 & L.P. & 33 & M & none & normal & neg. $T$ inf-lat. \\
\hline 12 & G.J. & 34 & M & none & normal & RVH, neg. $T$ inf-lat. \\
\hline 13 & T.C. & 37 & M & none & $\mathrm{S} 3, \mathrm{~S} 4$ & neg. $T$ ant-lat. \\
\hline 14 & G.G. & 40 & $\mathrm{~F}$ & none & S 4 & neg. $T$ inf-lat. \\
\hline 15 & G.H. & 45 & $\mathrm{~F}$ & none & normal & VPC, APC, IST lat. \\
\hline
\end{tabular}

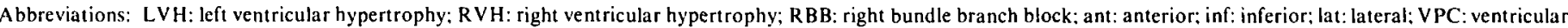
premature contractions; APC: atrial premature contractions; WPW: Wolff-Parkinson-White Syndrome; neg: negative. 
absence of symptoms. Two-thirds of the patients had a symmetrical, concentric hypertrophy. One patient had an unusual diffuse myopathic process with lack of thickening of the septum and of the posterior wall.

The best early indicator of myocardial involvement appears to be the presence of ECG abnormalities. These may precede neurological signs by many years, and, often, severe ECG alterations may be found in asymptomatic patients (Maron et al, 1978). All our patients had abnormal ECG and VCG; the ECG showed mainly ST-T alterations.

It is interesting to note the occasional discrepancy between the topography of the ventricular hypertrophy as diagnosed by electrocardiogram or vectocardiogram. Thus one of the patients in our series had right ventricular hypertrophy on the ECG and left ventricular hypertrophy by echocardiographic examination; this may be due in part to the thoracic deformities.

The role of echocardiography has recently been emphasized in the assessment of hypertrophic cardiomyopathies in general (Abbasi et al, 1973; Henry et al, 1973) and in Friedreich's ataxia in particular (Smith et al, 1977). In 10 patients $(66 \%)$, we found evidence of symmetric concentric hypertrophy. In two of these patients who had a systolic ejection murmur, the existence of an outflow obstruction at rest may be suspected. In one of them, a systolic anterior motion of the mitral valve was documented which might possibly produce an outflow obstruction even in the absence of asymmetric septal hypertrophy (ASH) (Mintz et al, 1978; Maron et al, 1978). Our results are in keeping with the previous report by Côté et al (1976), but are at variance with Smith's et al findings (1977). In all patients with $\mathrm{FA}$, he found an $\mathrm{ASH}$ (ST/PWT ratio from 1.5 to 2.3) in four patients. There was no case of symmetric, concentric hypertrophy. The patient selection may be different. Our patients were significantly older (mean age 27.6) than those reported in his series (mean age 19 years), and in spite of their older age they had a much less severe form of FA. That a symmetric, concentric hypertrophy

TABLE 2

Echocardiographic Data

\begin{tabular}{cccccccc}
\hline Pt & LVID $_{d}$ & LVID & \% sh & ST & PWT & ST/PWT & Mitral valve \\
\hline 1 & 30 & 20 & 33 & 15 & 15 & 1.0 & \\
2 & 38 & 23 & 39 & 16 & 15 & 1.06 & SAM \\
3 & 32 & 20 & 37 & 14 & 13 & 1.0 & \\
4 & 35 & 25 & 28 & 10 & 9 & 1.1 & \\
5 & 45 & 25 & 44 & 10 & 9 & 1.1 & \\
6 & 40 & 28 & 40 & 13 & 13 & 1.0 & MVP \\
7 & 35 & 15 & 57 & 14 & 14 & 1.0 & \\
8 & 45 & 45 & - & 10 & 9 & 1.1 & PSM \\
9 & 38 & 22 & 42 & 13 & 13 & 1.0 & \\
10 & 30 & 20 & 33 & 10 & 9 & 1.1 & \\
11 & 50 & 30 & 40 & 11 & 10 & 1.1 & \\
12 & 36 & 20 & 44 & 14 & 14 & 1.0 & \\
13 & 42 & 27 & 35 & 15 & 15 & 1.0 & \\
14 & 38 & 20 & 47 & 13 & 13 & 1.0 & \\
15 & 40 & 27 & 32 & 13 & 13 & 1.0 & \\
\hline
\end{tabular}

Abbreviations: $L V I D_{\mathrm{d}}$ : left vent ricular interval diameter in diastole; \% sh: percent of minor axis shortening. LVID, left ventricular interval diameter in systole: SAM: systolic anterior motion of the anterior initial leaflet; MVP: Mitral valve prolapse; PSM: paradoxical septal motion (with lack of systolic thickening).

may occur initially or occur in milder forms of FA is suggested by our study. Whether these symmetric forms later progress to asymmetric septal hypertrophy is not known.

Smith et al (1977) have suggested that in FA, the myocardial and neurological abnormalities represent pleiotropic effects of the same deleterious gene. However, the hypertrophic cardiomyopathies observed in this setting could be a form of neurologicallyinduced heart disease. Polani and Moynahan (1972) observing the occasional association between lentiginosis and hypertrophic cardiomyopathies have postulated that myocardial and segmental abnormalities could be due to a dysfunction of the elements of the embryonic neural crest. Goodwin (1974) has suggested that cardiomyopathies could result from an excessive production of catecholamines or from an abnormal response to these substances by the developing myocardium. It is of interest that we have found a significant elevation of circulating catecholamines (Pasternac et al, 1979) in patients with mitral valve prolapse.
Mitral valve prolapse was found to occur in association with hypertrophic cardiomyopathy in one of the patients of this series. Preliminary results from our laboratory suggest that plasma catecholamines are significantly elevated in some of our patients with FA.

Thus, one should stress the fact that patients with FA should undergo periodic echocardiographic examination to detect the presence of a cardiomyopathy. This could have practical relevance since calciumantagonist drugs are now available. A trial of these drugs seems particularly warranted in view of the work of Huxtable (1978) and Barbeau (1979) suggesting that the cardiomyopathy of Friedreich's ataxia could be related to a defect of calcium transfer across the cell membrane.

\section{REFERENCES}

ABBASI, A.S., MacALPIN, R.N., EBER, L.M. and PEARCE, M.L. (1973). Left ventricular hypert rophy diagnosed by echocardiography. N. Engl. J. Med. 289: 118-120.

BARBEAU, A. (1979). Friedrich's ataxia 1979; an overview. Can. J. Neurol. Sci. 6: 311-319. 
BOYER, S.H., CHISHOLM, A.W. and McKUSICK, V.A. (1962). Cardiac aspects of Friedreich's ataxia. Circulation 25: 49.3505.

CÔTÉ, M., DAVIGNON, A., PECKO-DROUIN, K., SOLIGNAC, A., GEOFFROY, G., LEMIEUX, B. and BARBEAU, A. (1976). Cardiological signs and symptoms in Friedreich's ataxia. Can. J. Neurol. Sci. 3: 319-321.

GACH, J.V., ADRIANGE, M. and FRANCK, G. (197I). Hypertrophic obstructive cardiomyopathy and Friedreich's ataxia. Report of a case and review of literature. Am. J. Cardiol. 27: 436-441.

GOODWIN, J.F. (1974). Prospects and predictions for the cardiomyopathies. Circulation 50: 210-219.

HENRY, W.L., CLARK, C.E. and EPSTEIN, S.E. (1973). Asymmetric septal hypertrophy. Echocardiographic identification of the pathognomonic anatomic abnormality of the IHSS. Circulation 47: 225-233.

HEWER, R.L. (1969). The heart in Friedreich's ataxia. Brit. Heart J, 31: 5-14

HUXTABLE, R. (1978). Cardiac pharmacology and cardiomyopathy in Friedreich's ataxia. Can. J. Neurol. Sci. 5: 83-91.

KISSLO, J., VON RAMM, O.T. and THURSTONE, F.L. (1976). Cardiac imaging using a phased array ultrasound system. II. Clinical technique and application. Circulation 53: 262-267.

MARON, B.J., GOTTDIENER, J.S., ROBERTS, W.C., HENRY, W.L., SAVAGE, D.D. and EPSTEIN, S.E. (1978). Left ventricular outflow tract obstruction due to systolic anterior motion of the anterior mitral leaflet in patients with concentric left ventricular hypertrophy. Circulation 57: 527-533.

MINTZ, G.D., KOTLER, M.N., SEGAL, B.L. and PARRY, W.R. (1978). Systolic anterior motion of the mitral valve in the absence of asymmetric septal hypertrophy. Circulation 57: $256-263$.

PASTERNAC, A., TUBAU, J., COUSINEAU, D, and DE CHAMPLAIN, J. (1979). Increased plasma catecholamines in symptomatic mitral valve prolapse. Circulation 60 (Suppl. II): II-156.

PERNOT, C. (1979). La myocardiopathie de la maladie de Friedreich. A propos d'une série de 17 observations. Arch. Fr. Pediatr. 36: 1118.

POLANI, P.E. and MOYNAHAN, E.J. (1972). Progressive cardiomyopathic lentiginosis. Q. J. Med. 41: 205.

ROSING, D.R., KENT, K.M., BORER, I.S., SEIDES, S.F., MARON, B.J. and EPSTEIN,
S.E. (1979a). Verapamil therapy: a new approach to the pharmacologic treatment of hypertrophic cardiomyopathy. Circulation 60): $1201-1207$

ROSING, D.R., KENT, K.M., MARON, B.J. and EPSTEIN, S.E. (1979b). Verapamil therapy: a new approach to the pharmacologic treatment of hypertrophic cardiomyopathy. 11. Effects on exercise capacity and symptomatic status. Circulation 60: 1208-1213.

RUSCHHAUPT, D.G., THILENIUS, O.G. and CASSELS, D.E. (1973). Friedreich's ataxia associated with idiopathic hypertrophic subaortic stenosis. Am. Heart J. 84: 95-102.

SMITH, E.R., SANGALANG, V.E., HEFFERNAN, L.P., WELCH, J.P. and FLEMINGTON, C.S. (1977). Hypertrophic cardiomyopathy: the heart disease of Friedreich's ataxia. Am. Heart J. 94: 428434.

THOREN, C. (1964). Cardiomyopathy in Friedreich's ataxia: with studies of cardiovascular and respiratory functions. Acta Paediat. 53 (Suppl. 153): 153.

TROESCH, M., HIRZEL, H.O., JENNI, R. and KRAYENBUHL, H.P. (1979). Reduction of septal thickness following verapamil in patients with asymmetric septal hypertrophy. Circulation 60 (Suppl. II): Il-155. 